\title{
Impact of pregnancy on vitamin D status: a longitudinal study
}

\author{
Joy Y. Zhang ${ }^{1}$, Alice J. Lucey ${ }^{1}$, Richard Horgan ${ }^{2}$, Louise C. Kenny ${ }^{2}$ and Mairead Kiely ${ }^{1,2 *}$ \\ ${ }^{1}$ Vitamin D Research Group, School of Food and Nutritional Sciences, University College Cork, Cork, Republic of Ireland \\ ${ }^{2}$ The Irish Centre for Fetal and Neonatal Translational Research (INFANT), Department of Obstetrics and Gynaecology, \\ University College Cork, Cork, Republic of Ireland \\ (Submitted 22 October 2013 - Final revision received 25 March 2014 - Accepted 7 April 2014 - First published online 27 August 2014)
}

\section{Abstract}

Nutritional requirements for vitamin D during pregnancy have been inadequately described, and there are conflicting data on the impact of gestation on vitamin D status. In the present study, we conducted a longitudinal analysis of total and free (unbound) serum 25-hydroxyvitamin D $(25(\mathrm{OH}) \mathrm{D})$, vitamin D-binding protein (DBP) and albumin concentrations in a random sample of thirty women from the Screening for Pregnancy Endpoints Ireland pregnancy cohort study at 15, 20, 24, 28, 32, 36 and 40 weeks of gestation and at 2 months postpartum. Concentrations of serum $25(\mathrm{OH}) \mathrm{D}, \mathrm{DBP}$ and albumin were determined, and free $25(\mathrm{OH}) \mathrm{D}$ was calculated from the concentrations of total $25(\mathrm{OH}) \mathrm{D}, \mathrm{DBP}$ and albumin. Serum albumin concentration decreased during pregnancy $(P<0 \cdot 001)$, with a nadir at 36 weeks $(P<0.005)$, during which the concentration was approximately $80 \%$ of the postnatal concentration. Serum DBP concentration increased during pregnancy and at 28 weeks of gestation, which was almost double the postnatal level $(P<0 \cdot 001)$. Total and free 25(OH)D concentrations decreased (both $P<0.005)$ as pregnancy progressed, and both were lowest at 36 weeks of gestation. At 15 weeks, 10 and $63 \%$ of the women had serum $25(\mathrm{OH}) \mathrm{D}$ concentration $<30$ and $50 \mathrm{nmol} / \mathrm{l}$, respectively, which increased to 53 and $80 \%$ at 36 weeks of gestation. The time course of decreasing concentrations of $25(\mathrm{OH}) \mathrm{D}$ during gestation among women recruited during May-July, who delivered between October and November, and among those recruited in August-September, who delivered between February and March, was similar. The lower percentage of free $25(\mathrm{OH}) \mathrm{D}$ during pregnancy is mainly due to increased DBP.

Key words: Vitamin D: 25-Hydroxyvitamin D: Pregnancy: Gestational stage

Pregnancy is a life stage at which significant changes in vitamin $\mathrm{D}$ and $\mathrm{Ca}$ metabolism occur to provide the required $\mathrm{Ca}$ to the fetus for bone mineral accretion; however, nutritional requirements for vitamin $\mathrm{D}$ to promote healthy pregnancy are not known. The current suggested cut-offs for serum 25-hydroxyvitamin $\mathrm{D}(25(\mathrm{OH}) \mathrm{D})$ concentrations representing vitamin $\mathrm{D}$ sufficiency/deficiency are based on the evidence from non-pregnant adults; however, it remains to be established whether there is an increased requirement for vitamin D intake during pregnancy and lactation ${ }^{(1,2)}$.

A challenge of assessing vitamin D status during pregnancy is haemodilution. The expansion of maternal plasma volume begins as early as 6 weeks of gestation and continues until it reaches a net $40 \%$ increase at 24-34 weeks of gestation ${ }^{(3)}$ and an approximately $50 \%$ increase by 36 weeks of gestation ${ }^{(4)}$. Thus, circulating concentrations of most nutrients decrease by the end of the first 10 weeks of gestation and remain lower than non-pregnancy values until term, even though the absolute total amount of vitamins and minerals in the circulation actually increases during pregnancy ${ }^{(5)}$. The increased blood volume during pregnancy is evidenced by the reduction in the concentration of circulating serum albu$\min ^{(6)}$. Reference values for serum 25(OH)D concentrations based on non-pregnant adults are not necessarily suitable at different stages of gestation due to the haemodilution that occurs during pregnancy as well as potentially altered vitamin D metabolism, which is not completely understood. Gestational age-specific reference intervals for serum 25(OH)D concentrations during pregnancy are required ${ }^{(7,8)}$.

Cord $25(\mathrm{OH}) \mathrm{D}$ concentrations are correlated with maternal levels during late pregnancy and at delivery ${ }^{(9,10)}$, which confirms the placental transfer of $25(\mathrm{OH}) \mathrm{D}$ during pregnancy. However, it has been suggested that the concentration of free (unbound) rather than total $25(\mathrm{OH}) \mathrm{D}$ is an important determinant of the placental transfer of $25(\mathrm{OH}) \mathrm{D}$. An earlier study ${ }^{(11)}$ has reported that although total $25(\mathrm{OH}) \mathrm{D}$ concentration is lower in cord than in maternal serum, the concentration of free $25(\mathrm{OH}) \mathrm{D}$ is higher in cord. Concentrations of free

Abbreviations: 1,25(OH) 2 D, 1,25-dihydroxyvitamin D; 25(OH)D, 25-hydroxyvitamin D; DBP, vitamin D-binding protein; SCOPE, Screening for Pregnancy Endpoints. 
$25(\mathrm{OH}) \mathrm{D}$ are dependent on the capacity of vitamin D-binding protein $(\mathrm{DBP})^{(12)}$, the major carrier of vitamin $\mathrm{D}$ and its metabolites to their target tissues in the human circulation. Concentrations of DBP increase during pregnancy from as early as 8 to 10 weeks of gestation ${ }^{(13)}$, followed by an increase in serum $1,25(\mathrm{OH})_{2} \mathrm{D}$ levels at about 10 to 12 weeks $^{(14)}$. However, the magnitude of the increase in DBP varies among studies ${ }^{(13,15,16)}$.

If $\mathrm{DBP}$ concentration increases to the extent that the concentration of free serum $25(\mathrm{OH}) \mathrm{D}$ is reduced, this could have a significant impact on the availability of maternal and fetal free $25(\mathrm{OH}) \mathrm{D}$ for biological activity. There is also the possibility that DBP increases to maintain the ratio of free $25(\mathrm{OH}) \mathrm{D}$ at a consistent level throughout gestation. The aim of the present study was to assess longitudinal changes in total and free serum 25(OH)D concentrations, serum albumin and DBP concentrations in a sample of thirty women throughout pregnancy, as well as postpartum, and to attempt to describe the impact of the gestational stage by assessing serum albumin concentrations as an indicator of haemodilution.

\section{Methods}

\section{Study design}

A total of 1768 participants who attended for antenatal care at Cork University Maternity Hospital, Cork Ireland $\left(52^{\circ} \mathrm{N}\right)$ were recruited to the Screening for Pregnancy Endpoints (SCOPE) Ireland pregnancy cohort study (http://www.scopestudy.net) before 15 weeks of gestation, between March 2008 and January 2011. The SCOPE study is an international pregnancy cohort study with the primary aim of developing screening tests to predict pre-eclampsia, infants who are small for gestational age, and spontaneous preterm birth. There were six research centres in four countries: Auckland, New Zealand; Adelaide, Australia; London, Leeds and Manchester, UK; Cork, Ireland. Data collected in Ireland were analysed in the present study. The SCOPE study was conducted according to the Declaration of Helsinki guidelines, and the Clinical Research Ethics Committee of the Cork Teaching Hospitals approved all procedures. All women provided written informed consent at first visit (14-16 weeks of gestation). The SCOPE study is registered at the Australian, New Zealand Clinical Trials Registry (http://www.anzctr.org.au, ID: ACTRN $12607000551493)^{(17)}$.

The main inclusion criteria were low-risk pregnancy; singleton pregnancy before 15 weeks of gestation; nulliparous; not having had a previous pregnancy beyond 20 weeks of gestation. Information on demography, medical history, use of multivitamin supplements, alcohol consumption, and the use of cigarettes and/or recreational drugs were recorded before conception, during the first trimester, and at the time of the 15-week visit. Physical activity was assessed on work, exercise and sedentary activities by a lifestyle questionnaire. Maternal anthropometric measurements included height and weight, which were measured by a research midwife at the first visit only. Weight was measured to the nearest $100 \mathrm{~g}$, without shoes or jacket, using calibrated scales. Height was measured to the nearest centimetre using a stadiometer, without shoes, according to SCOPE standard operating procedures. A non-fasting blood sample was taken from each participant and was processed within $3 \mathrm{~h}$ to serum, and stored at $-80^{\circ} \mathrm{C}$ for future analysis.

For the present nested longitudinal study, thirty Caucasian women were randomly selected at the time of recruitment to the SCOPE cohort between May and September 2009 and delivered between November and March 2010. Women participating in SCOPE Ireland had a maximum of three SCOPE visits: at 15 and 20 weeks of gestation and one visit in the third trimester. Women in the present study were sampled more frequently; non-fasting blood samples were collected at 15,20,24, 28, 32, 36 and 40 weeks of gestation and at approximately 9 weeks postpartum (range 8-10 weeks). Every member of the subsample had uneventful deliveries of healthy infants.

\section{Biomarker analysis}

Serum 25(OH)D concentration was measured using enzyme immunoassay (OCTEIA ${ }^{\circledR}$ 25-Hydroxy Vitamin D; Immunodiagnostic Systems Limited). The inter- and intra-assay CV were 8.3 and $4.0 \%$. The quality and accuracy of $25(\mathrm{OH}) \mathrm{D}$ analysis in our laboratory was assessed on an on-going basis by participation in the Vitamin D External Quality Assessment Scheme (Charing Cross Hospital, London, UK). Inter-assay variability was avoided by analysing all samples from an individual in the same run.

Serum concentrations of DBP were measured by Quantikine HS ELISA Kits (R\&D Systems). The inter- and intra-assay CV were $<10 \%$, respectively. Serum albumin concentration was measured by colorimetric assay using Randox Albumin Reagent kits (Randox Laboratories Limited), according to the manufacturer's instructions. The inter- and intra-assay $\mathrm{CV}$ were $5 \cdot 1$ and $1.5 \%$.

Free concentrations of $25(\mathrm{OH}) \mathrm{D}$ were calculated (pmol/l) using the following equation (all concentrations in molar units) ${ }^{(12)}$ :

Free $25(\mathrm{OH}) \mathrm{D}=\frac{\operatorname{total} 25(\mathrm{OH}) \mathrm{D}}{1+\left(6 \times 10^{3} \times \text { albumin }\right)+\left(7 \times 10^{8} \times \mathrm{DBP}\right)}$.

The reported correlation coefficient between calculated free $25(\mathrm{OH}) \mathrm{D}$ using this equation and measured free $25(\mathrm{OH}) \mathrm{D}$ by centrifugal ultrafiltration is $0.925^{(12)}$.

\section{Statistical analyses}

Sample size was selected based on previous data from crosssectional studies and randomised controlled trials carried out by our research group, which have consistently indicated that a sample size of approximately 30 is sufficient at $80 \%$ power and a significance level of $5 \%$ to detect a $10 \mathrm{nmol} / 1$ difference between groups, which we estimated as a clinically relevant difference over time in the present longitudinal analysis. Statistical analyses were carried out using $\mathrm{PASW}^{\circledR}$ Statistics version 20.0 (SPSS, IBM). The analysis of baseline 
data (at 15 weeks of gestation) revealed that serum albumin, 25(OH)D and DBP concentrations followed a parametric distribution. Free 25(OH)D concentrations were logtransformed. The overall change during pregnancy over time was analysed by repeated-measures ANOVA using the general linear model. Comparison between two time points (e.g. any pregnancy time point $v$. postpartum) and the magnitude of change between two adjacent time points were analysed using paired $t$ tests. Partial correlations between serum $25(\mathrm{OH}) \mathrm{D}$, free $25(\mathrm{OH}) \mathrm{D}$, albumin, DBP and albumin adjusted-25(OH)D concentrations were carried out with gestational week as the covariate. Results were considered as statistically significant at $P \leq 0 \cdot 05$.

\section{Results}

Baseline characteristics of the thirty pregnant women at 15 weeks of gestation are presented in Table 1 . The age range of the participants was from late 20 s to early $30 \mathrm{~s}$, with an average BMI of $23.5 \mathrm{~kg} / \mathrm{m}^{2}$. Of these participants, one-third were taking a vitamin D-containing supplement, with a daily dose ranging from 2.5 to $10 \mu \mathrm{g} / \mathrm{d}$, and $13 \%$ were taking a Ca-containing supplement. The calculated free $25(\mathrm{OH}) \mathrm{D}$ concentration was $0.02 \%$ of the total serum $25(\mathrm{OH}) \mathrm{D}$. Age and BMI were not associated with DBP, total or free $25(\mathrm{OH}) \mathrm{D}$. Both age $(\beta=-0.367, \quad P=0.047)$ and BMI ( $\beta=-0.333, \quad P=0.067)$ were negatively associated with albumin concentrations at 15 weeks of gestation $(P=0.053)$ and together accounted for $20 \%$ of the variability in albumin concentrations at baseline. Consumption of vitamin D or Ca-containing supplements was not associated with total or free $25(\mathrm{OH}) \mathrm{D}$ concentrations at 15 weeks of gestation, which may be due to the small sample size and relatively small dosage.

During gestation, an overall decrease in total $25(\mathrm{OH}) \mathrm{D}$ concentrations was observed from 15 weeks of gestation to term $(P=0.002)$, with a nadir at 36 weeks (see Table 2 and Fig. 1(a)). As a result, the proportion of women with serum $25(\mathrm{OH}) \mathrm{D}$ concentration $<30$ and $50 \mathrm{nmol} / \mathrm{l}^{(1)}$ was 10 and $63 \%$, respectively, at 15 weeks of gestation and increased to 53 and $80 \%$, respectively, at 36 weeks of gestation. As the entire subsample was recruited between May and September, we compared longitudinal changes in total $25(\mathrm{OH}) \mathrm{D}$

Table 1. Baseline characteristics of the thirty women at 15 weeks of gestation

(Mean values, standard deviations and percentages)

\begin{tabular}{|c|c|c|}
\hline & Mean & SD \\
\hline Age (years) & $30 \cdot 4$ & 3.0 \\
\hline BMI $\left(\mathrm{kg} / \mathrm{m}^{2}\right)$ & 23.5 & 3.5 \\
\hline Use of a vitamin D-containing supplement (\%) & \multicolumn{2}{|c|}{33.3} \\
\hline Use of a Ca-containing supplement (\%) & \multicolumn{2}{|c|}{$13 \cdot 3$} \\
\hline Serum albumin (g/l) & $39 \cdot 0$ & $2 \cdot 3$ \\
\hline Serum 25(OH)D (nmol/l) & $49 \cdot 9$ & $16 \cdot 5$ \\
\hline Serum DBP (mg/l) & $424 \cdot 3$ & $157 \cdot 9$ \\
\hline Free 25(OH)D (pmol/l) & 11.09 & $7 \cdot 6$ \\
\hline Percentage of free $25(\mathrm{OH}) \mathrm{D}$ & 0.022 & 0.01 \\
\hline
\end{tabular}

25(OH)D, 25-hydroxyvitamin D; DBP, vitamin D-binding protein. concentrations of women recruited during early summer (May-July, who delivered between October and November) and late summer (August-September, who delivered between February and March) (see Fig. 2) . After an initial slight increase in the concentrations of total $25(\mathrm{OH}) \mathrm{D}$ in women recruited during May-June, the pattern of decreasing $25(\mathrm{OH}) \mathrm{D}$ concentrations during pregnancy was similar in the two subgroups, although those recruited in late summer exhibited a more rapid decline in $25(\mathrm{OH}) \mathrm{D}$ concentrations, which is typical of the seasonal variation at this northerly latitude $\left(52^{\circ} \mathrm{N}\right)$.

Serum DBP concentrations at 15 weeks of gestation were significantly elevated compared with the postnatal level $(P<0 \cdot 001)$. DBP concentrations continued to increase steadily from 15 to approximately 32 weeks of gestation, peaking at 28 weeks, at almost double the postnatal concentration (see Table 2 and Fig. 1(b)). Although there was a slight decrease in DBP concentrations in the last weeks of pregnancy, concentrations were still significantly higher before delivery than postpartum, and the decrease was dramatic after giving birth $(P<0.001)$. The increase in DBP concentrations during pregnancy was against the haemodilution gradient, which was evidenced by the decrease in albumin concentrations (Fig. 1(c)). Serum albumin concentration was $86 \%$ of the postnatal level at 15 weeks of gestation, $83 \%$ between 20 and 28 weeks of gestation and approximately $80 \%$ from week 32 until term $(P<0 \cdot 001)$, with the lowest concentration at 36 weeks of gestation (see Table 2). Albumin concentrations at all the seven time points during pregnancy were significantly lower than the postnatal level (all $P<0 \cdot 001$ ).

Similar to total $25(\mathrm{OH}) \mathrm{D}$, free $25(\mathrm{OH}) \mathrm{D}$ concentrations also decreased from 15 weeks of gestation to delivery $(P=0 \cdot 016)$, reaching a nadir at 36 weeks, the same time course as that observed for serum albumin (see Fig. 1(d)). Free 25(OH)D concentrations at all the seven time points during pregnancy were lower than the postnatal level (all $P<0 \cdot 001$ ). While the percentage of free over total serum $25(\mathrm{OH}) \mathrm{D}$ concentrations did not differ significantly during pregnancy, it was significantly lower than the postnatal value at all time points (Table 2). Using partial correlation and adjusting for week of gestation, associations $(r)$ between serum total and free $25(\mathrm{OH}) \mathrm{D}$ concentrations were consistently high ranging from 0.59 at 15 weeks of gestation to 0.80 at 40 weeks of gestation, decreasing to 0.59 in the postnatal sample. Similarly, total $25(\mathrm{OH}) \mathrm{D}$ adjusted for serum albumin was consistently positively associated with free $25(\mathrm{OH}) \mathrm{D}$ throughout pregnancy, increasing from an $r$ value of 0.56 at week 15 to 0.81 at week 40 but decreasing to 0.58 postpartum (all $P<0.05$ ). As expected, there was a negative association between free $25(\mathrm{OH}) \mathrm{D}$ and DBP concentrations throughout pregnancy $(r-0.47$ to -0.67$)$ and no association between DBP and total $25(\mathrm{OH}) \mathrm{D}$ concentrations, although postnatal serum 25(OH)D concentration was associated with DBP ( $r 0 \cdot 444)$.

\section{Discussion}

It has been suggested for some time ${ }^{(12)}$ that free $25(\mathrm{OH}) \mathrm{D}$ may be a more sensitive indicator of biologically available 
$25(\mathrm{OH}) \mathrm{D}$ than total circulating 25(OH)D. During pregnancy, a combination of haemodilution and increasing DBP concentrations may significantly reduce the concentration of free $25(\mathrm{OH}) \mathrm{D}$ in the circulation. Therefore, in the present study, we conducted a longitudinal analysis of total and free serum $25(\mathrm{OH}) \mathrm{D}, \mathrm{DBP}$ and albumin concentrations in a random sample of thirty women from a prospective pregnancy cohort, with sampling made at seven time points at 4-weekly intervals from 15 to 40 weeks of gestation and postpartum. While sampling was not seasonally balanced, which is a serious drawback, the data showed that as pregnancy progressed, total serum 25(OH)D concentrations decreased, even throughout summer. Free $25(\mathrm{OH}) \mathrm{D}$ was strongly correlated with $25(\mathrm{OH}) \mathrm{D}$ throughout gestation. Progressively decreasing serum albumin concentrations indicated increases in blood volume. Serum DBP concentrations increased throughout gestation against the haemodilution gradient. While absolute concentrations of free $25(\mathrm{OH}) \mathrm{D}$ decreased in line with increasing DBP, the percentage of free $25(\mathrm{OH}) \mathrm{D}$ concentrations did not vary much during pregnancy but increased substantially postpartum as the DBP level declined.

Studies investigating vitamin D and its metabolism during pregnancy have been mainly cross-sectional, and longitudinal studies have limited sampling points during pregnancy. Bouillon et al. ${ }^{(16)}$ measured DBP, 1,25-dihydroxyvitamin D $\left(1,25(\mathrm{OH})_{2} \mathrm{D}\right)$, total and free $25(\mathrm{OH}) \mathrm{D}$ concentrations at four different time points (18, 32, 35 and 40 weeks) among forty women, and reported significantly increased levels of DBP, $1,25(\mathrm{OH})_{2} \mathrm{D}$ and reduced free $25(\mathrm{OH}) \mathrm{D}$ at all time points during pregnancy compared with non-pregnant controls. In contrast, total $25(\mathrm{OH}) \mathrm{D}$ concentrations during pregnancy were not significantly different from non-pregnant controls, except at 18 weeks of gestation where a significantly higher level has been reported. Seasonal variations were found in total $25(\mathrm{OH}) \mathrm{D}$ concentrations at delivery; however, the season of recruitment was not recorded in this study, and the reason why the levels of total $25(\mathrm{OH}) \mathrm{D}$ were higher at 18 weeks of gestation was not clear.

Cross et al. ${ }^{(14)}$ examined serum 25(OH)D and $1,25(\mathrm{OH})_{2} \mathrm{D}$ concentrations at each trimester among ten women, and reported increased levels of $1,25(\mathrm{OH})_{2} \mathrm{D}$ at the second and third trimesters. A gradual increase in $25(\mathrm{OH}) \mathrm{D}$ concentrations was observed, which were significantly higher in the third trimester compared with non-pregnant controls. However, seasonal variation in $25(\mathrm{OH}) \mathrm{D}$ concentrations was not considered. Ritchie et al. ${ }^{(13)}$ followed fourteen women from pre-pregnancy to post-menses and analysed the concentrations of $25(\mathrm{OH}) \mathrm{D}$ and $1,25(\mathrm{OH})_{2} \mathrm{D}$ pre- and postpregnancy, and at each trimester. They have reported a continuous increase in the concentrations of $1,25(\mathrm{OH})_{2} \mathrm{D}$ during pregnancy, and concentrations at the second and third trimesters were significantly higher than pre- and post-pregnancy levels. In this study, no change in the concentrations of 25(OH)D during pregnancy has been reported, but again, seasonal variation in $25(\mathrm{OH}) \mathrm{D}$ concentrations was not considered.

More et al. ${ }^{(18)}$ assessed 25(OH)D concentrations in a cohort of twenty women, but at only one time point during 

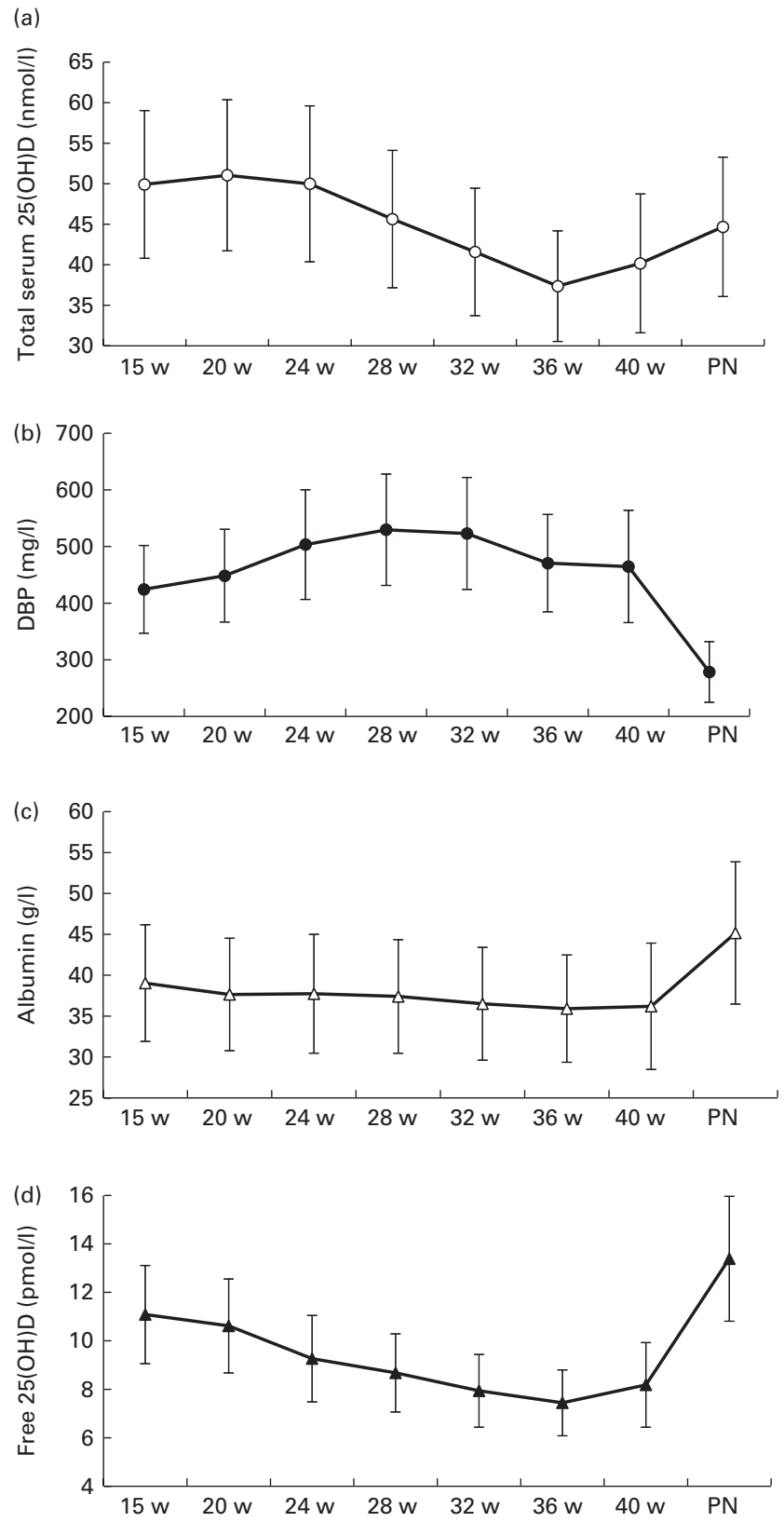

Fig. 1. Longitudinal changes in circulating (a) total 25-hydroxyvitamin $D$ $(25(\mathrm{OH}) \mathrm{D})$, (b) vitamin D-binding protein (DBP), (c) albumin and (d) free $25(\mathrm{OH}) \mathrm{D}$ concentrations during pregnancy and postnatal $(\mathrm{PN})$ period. Values are means, with their standard errors represented by vertical bars. w, Weeks.

pregnancy (22-24 weeks of gestation), and reported no difference in the concentrations of $25(\mathrm{OH}) \mathrm{D}$ before, during and after pregnancy. Narchi et $a l^{(19)}$ followed a cohort of women from early pregnancy $(n 75)$ to shortly after delivery ( $n$ 47) and 6 months after delivery ( $n$ 24), and reported a progressive decrease in the concentrations of 25(OH)D; however, the recruitment in this study occurred during late summer (September-November). A prospective study carried out by Fernandez-Alonso et $a l .^{(20)}$ in Spain reported a significant decrease in $25(\mathrm{OH}) \mathrm{D}$ concentrations from the first to the third trimester in 148 pregnant women, independent of the season of sampling. Interestingly, a comparative study carried out by Sanchez et $a l^{(21)}$ among Nigerian pregnant teenagers has reported a significant decrease in the concentrations of $25(\mathrm{OH}) \mathrm{D}$ in the first trimester, no difference in the second trimester, and an increase in the concentrations of $25(\mathrm{OH}) \mathrm{D}$ in the third trimester compared with non-pregnant controls. In addition, albumin concentrations were significantly lower in women during pregnancy, especially in the second and third trimesters. We conducted a prospective study ${ }^{(22)}$ in a small pregnancy cohort $(n 43)$ in Cork, Ireland $\left(52^{\circ} \mathrm{N}\right)$. We reported a gradual decrease in the prevalence of vitamin $\mathrm{D}$ deficiency indicated by an increase in the concentrations of $25(\mathrm{OH}) \mathrm{D}$ as pregnancy progressed. We also found that the levels of serum $25(\mathrm{OH}) \mathrm{D}$ concentrations were dramatically influenced by season. A longitudinal study carried out by Holmes et al. ${ }^{(23)}$ among 120 pregnant subjects in Northern Ireland $\left(55^{\circ} \mathrm{N}\right)$ has reported that the levels of $25(\mathrm{OH}) \mathrm{D}$ in all trimesters were lower than those found in non-pregnancy controls in the same season, although there was a slight increase in $25(\mathrm{OH}) \mathrm{D}$ concentrations as pregnancy progressed, which could be due to the season of baseline sampling (12 weeks of gestation) during winter.

A meta-analysis carried out by Papapetrou ${ }^{(24)}$ assessed the relationship between the concentrations of circulating $25(\mathrm{OH}) \mathrm{D}$ and $1,25(\mathrm{OH})_{2} \mathrm{D}$, during pregnancy at term, and reported that the $25(\mathrm{OH}) \mathrm{D}$ levels during pregnancy were not different from the levels found in non-pregnancy, but the $1,25(\mathrm{OH})_{2} \mathrm{D}$ levels were two-fold higher in pregnancy than
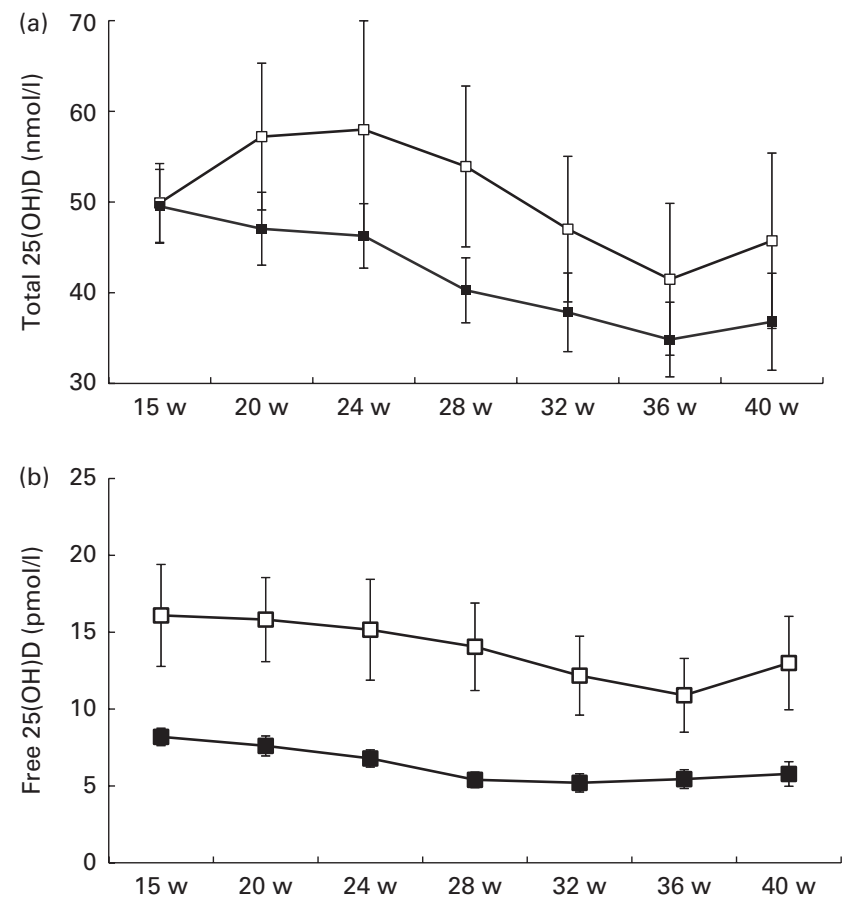

Fig. 2. Longitudinal changes in circulating total and free $25(\mathrm{OH}) \mathrm{D}$ concentrations in women recruited at 15 weeks of gestation in early summer $(\square, n 11$, May-July, who delivered between October and November) and late summer (ם, $n$ 19, August-September, who delivered between February and March). Values are means, with their standard errors represented by vertical bars. w, Weeks. 
during non-pregnancy. However, the conclusion did not consider the impact of haemodilution. Although elevated $1,25(\mathrm{OH})_{2} \mathrm{D}$ concentrations during pregnancy have been consistently reported, changes in the concentrations of $25(\mathrm{OH}) \mathrm{D}$ during pregnancy are contradictory, and not all studies consider the effect of season. These studies are inconclusive as they are either small, cross-sectional or with few sampling points and inadequate accounting for the seasonal effect.

DBP is the major carrier of vitamin D and its derivatives. We reported an increase in DBP concentrations during pregnancy, peaking at 28 weeks of gestation, which were almost twice the postnatal levels. Increases in the concentrations of DBP during pregnancy have been reported previously, although the magnitude of the increase in the concentrations of DBP during pregnancy varies ${ }^{(13,15,16)}$. Bouillon et al.$^{(16)}$ reported a doubling in the concentrations of DBP from 18 weeks of gestation until term compared with non-pregnant subjects. Ritchie et al. ${ }^{(13)}$ reported increased DBP concentrations during pregnancy in fourteen women; the levels were highest between 23 and 26 weeks of gestation (50\% higher than pre-pregnancy) and returned to pre-pregnant levels during early lactation and post-menses. A comparative study carried out by Bikle et al. ${ }^{(15)}$ has reported that pregnant subjects ( $n$ 17) had $40 \%$ higher concentrations of DBP during the third trimester compared with non-pregnant subjects $(n 24)$. The increase in DBP concentrations during pregnancy was accompanied by an increase in the concentrations of serum $1,25(\mathrm{OH})_{2} \mathrm{D}$. In three longitudinal studies, the concentrations of $1,25(\mathrm{OH})_{2} \mathrm{D}$ have been reported to significantly increase at all time points during pregnancy, with the concentration being highest in the third trimester ${ }^{(13,14)}$, or near term ${ }^{(16)}$, which was more than double the pre-pregnant levels.

Free $25(\mathrm{OH}) \mathrm{D}$ concentrations reported in the present study were calculated based on the total serum $25(\mathrm{OH}) \mathrm{D}$, albumin and DBP concentrations, using the equation adopted from Bikle et $a l^{(12)}$. We showed a consistent decrease in free $25(\mathrm{OH}) \mathrm{D}$ concentrations from 15 to 36 weeks of gestation and a significantly lower percentage of free $25(\mathrm{OH}) \mathrm{D}$ concentrations during pregnancy compared with the postnatal value. The reduced percentage of free $25(\mathrm{OH}) \mathrm{D}$ concentrations was probably due to the increased concentrations of DBP during pregnancy. To date, only one study has reported free $25(\mathrm{OH}) \mathrm{D}$ concentrations during pregnancy. A comparative cross-section study carried out by Bouillon et al. ${ }^{(11)}$ examined free $25(\mathrm{OH}) \mathrm{D}$ concentrations in maternal and cord serum at the time of delivery. Although there was no comparison of maternal free $25(\mathrm{OH}) \mathrm{D}$ levels with postnatal or non-pregnant values, significantly higher concentrations of free $25(\mathrm{OH}) \mathrm{D}$ in cord than in maternal serum have been reported alongside lower total 25(OH)D concentrations in cord. Given that the free rather than the total concentration of $25(\mathrm{OH}) \mathrm{D}$ may be more significant in the placental transfer of $25(\mathrm{OH}) \mathrm{D}$, implications of a reduced percentage of free $25(\mathrm{OH}) \mathrm{D}$ concentrations may suggest the regulation of $25(\mathrm{OH}) \mathrm{D}$ transfer to the fetus, which warrants further investigation.

The present longitudinal study examined 25(OH)D and DBP concentrations at seven time points during gestation among thirty Caucasian women, which provided a unique opportunity to detect biological differences in vitamin D-related metabolites, taking haemodilution into consideration. The limitation of the present study was that as recruitment was between May and September, it was not seasonally balanced and the effect of season on 25(OH)D could not be fully accounted for. Nonetheless, with the exception of a seasonal slight increase in the concentrations of total $25(\mathrm{OH}) \mathrm{D}$ in women recruited in May-June at their second sample, which would have been taken during the annual peak in July, the time course of decreasing 25(OH)D concentrations observed in women who progressed through their pregnancy during summer-autumn and delivered between October and November was similar to those who progressed during autumn-winter and delivered between February and March. In addition, we were unable to measure the concentrations of $1,25(\mathrm{OH})_{2} \mathrm{D}$ due to the insufficient sample volume, which is an area for future investigation. Overall, the present study contributes to the current knowledge of vitamin D metabolism during pregnancy, which ultimately aims to provide a better understanding of the changes in vitamin D status as gestation progresses and the prevention of vitamin D deficiency in women and newborn infants. Dose-response randomised controlled trials with multiple sampling points and complete year-round sampling at baseline during early pregnancy would provide a definitive solution to nutritional requirements for vitamin D during gestation. Our data indicate a concomitant decrease in circulating total and free $25(\mathrm{OH}) \mathrm{D}$ concentrations as pregnancy advances, which suggests a higher requirement for vitamin D.

\section{Acknowledgements}

The present study was supported by the funding provided to M. K. from the Irish Government Department of Agriculture through the Food Institutional Research Measure, which supported J. Y. Z. and A. J. L. L. C. K. is a recipient of a Clinician Scientist Award from the Health Research Board of Ireland (grant no. CSA 2007/02) and a Principal Investigator award from Science Foundation Ireland (grant no. 08/IN.1/B2083).

The authors' contributions are as follows: M. K. and L. C. K. designed the research; L. C. K. and R. H. were responsible for data collection and biobanking; J. Y. Z. and A. J. L. conducted the sample analysis; J. Y. Z., A. J. L. and M. K. conducted the data analysis; J. Y. Z. and M. K. wrote the paper; M. K. had responsibility for the final content. All authors read and approved the final draft. The SCOPE database is provided and maintained by MedSciNet AB (http://medscinet.com).

The authors have no conflicts of interest to declare.

\section{References}

1. Institute of Medicine (2011) Dietary Reference Intakes for Calcium and Vitamin D. Washington, DC: The National Academies Press.

2. Brannon PM \& Picciano MF (2011) Vitamin D in pregnancy and lactation in humans. Annu Rev Nutr 31, 89-115.

3. Ross M \& Idah R (2004) Correlation of maternal plasma volume and composition with amniotic fluid index in normal human pregnancy. J Matern Fetal Neonatal Med 15, 104-108. 
4. Faupel-Badger JM, Hsieh CC, Troisi R, et al. (2007) Plasma volume expansion in pregnancy: implications for biomarkers in population studies. Cancer Epidemiol Biomarkers Prev 16, $1720-1723$.

5. King JC (2000) Physiology of pregnancy and nutrient metabolism. Am J Clin Nutr 71, 1218S-1225S.

6. De Flamingh JP \& van der Merwe JV (1984) A serum biochemical profile of normal pregnancy. S Afr Med J 65, 552-555.

7. Klajnbard A, Szecsi PB, Colov NP, et al. (2010) Laboratory reference intervals during pregnancy, delivery and the early postpartum period. Clin Chem Lab Med 48, 237-248.

8. Picciano MF (2003) Pregnancy and lactation: physiological adjustments, nutritional requirements and the role of dietary supplements. J Nutr 133, 1997S-2002S.

9. Dror DK, King JC, Durand DJ, et al. (2011) Association of modifiable and nonmodifiable factors with vitamin D status in pregnant women and neonates in Oakland, CA. J Am Diet Assoc 111, 111-116.

10. Bodnar LM, Simhan HN, Powers RW, et al. (2007) High prevalence of vitamin D insufficiency in black and white pregnant women residing in the northern United States and their neonates. J Nutr 137, 447-452.

11. Bouillon R, Van Baelen H \& De Moor P (1977) 25-Hydroxyvitamin $\mathrm{D}$ and its binding protein in maternal and cord serum. J Clin Endocrinol Metab 45, 679-684.

12. Bikle DD, Gee E, Halloran B, et al. (1986) Assessment of the free fraction of 25-hydroxyvitamin $\mathrm{D}$ in serum and its regulation by albumin and the vitamin D-binding protein. J Clin Endocrinol Metab 63, 954-959.

13. Ritchie LD, Fung EB, Halloran BP, et al. (1998) A longitudinal study of calcium homeostasis during human pregnancy and lactation and after resumption of menses. Am J Clin Nutr 67, 693-701.

14. Cross NA, Hillman LS, Allen SH, et al. (1995) Calcium homeostasis and bone metabolism during pregnancy, lactation, and postweaning: a longitudinal study. Am J Clin Nutr 61, 514-523.
15. Bikle DD, Gee E, Halloran B, et al. (1984) Free 1,25-dihydroxyvitamin D levels in serum from normal subjects, pregnant subjects, and subjects with liver disease. J Clin Invest 74, 1966-1971.

16. Bouillon R, Van Assche FA, Van Baelen H, et al. (1981) Influence of the vitamin D-binding protein on the serum concentration of 1,25-dihydroxyvitamin D3: significance of the free 1,25-dihydroxyvitamin D3 concentration. J Clin Invest 67, 589-596.

17. North RA, McCowan LM, Dekker GA, et al. (2011) Clinical risk prediction for pre-eclampsia in nulliparous women: development of model in international prospective cohort. BMJ 342, d1875.

18. More C, Bhattoa HP, Bettembuk P, et al. (2003) The effects of pregnancy and lactation on hormonal status and biochemical markers of bone turnover. Eur J Obstet Gynecol Reprod Biol 106, 209-213.

19. Narchi H, Kochiyil J, Zayed R, et al. (2010) Maternal vitamin D status throughout and after pregnancy. J Obstet Gynaecol 30, 137-142.

20. Fernandez-Alonso AM, Dionis-Sanchez EC, Chedraui P, et al. (2012) First-trimester maternal serum 25-hydroxyvitamin D status and pregnancy outcome. Int J Gynaecol Obstet 116, 6-9.

21. Sanchez P, Idrisa A, Bobzom D, et al. (1997) Calcium and vitamin D status of pregnant teenagers in Maiduguri, Nigeria. I Natl Med Assoc 89, 805-811.

22. O'Riordan MN, Kiely M, Higgins JR, et al. (2008) Prevalence of suboptimal vitamin D status during pregnancy. Ir Med J 101, 242-243.

23. Holmes VA, Barnes MS, Alexander HD, et al. (2009) Vitamin D deficiency and insufficiency in pregnant women: a longitudinal study. Br J Nutr 102, 876-881.

24. Papapetrou PD (2010) The interrelationship of serum 1,25-dihydroxyvitamin D, 25-hydroxyvitamin $\mathrm{D}$ and 24 , 25-dihydroxyvitamin $\mathrm{D}$ in pregnancy at term: a meta-analysis. Hormones 9, 136-144. 